\title{
Life Cycle Assessment of Green Diesel Production by Hydrodeoxygenation of Palm Oil
}

OPEN ACCESS

Edited by:

Luis Puigjaner,

Universitat Politecnica de Catalunya,

Spain

Reviewed by:

Murugesan Arthanarisamy, KSR college of Technology, India Mariano Martín,

University of Salamanca, Spain

*Correspondence: Luis Felipe Ramírez-Verduzco Iframir@imp.mx

Myriam Adela Amezcua-Allier mamezcua@imp.mx

Specialty section: This article was submitted to Process and Energy Systems

Engineering,

a section of the journa Frontiers in Energy Research

Received: 04 April 2021 Accepted: 28 May 2021

Published: 23 July 2021

Citation:

Arguelles-Arguelles A, Amezcua-Allieri MA and Ramírez-Verduzco LF (2021) Life Cycle Assessment of Green Diesel Production by Hydrodeoxygenation of

Palm Oil.

Front. Energy Res. 9:690725. doi: 10.3389/fenrg.2021.690725

\author{
Antonio Arguelles-Arguelles ${ }^{1}$, Myriam Adela Amezcua-Allieri ${ }^{2 *}$ and \\ Luis Felipe Ramírez-Verduzco ${ }^{2 *}$ \\ ${ }^{1}$ Posgraduate Department, Mexican Institute of Petroleum, Mexico City, Mexico, ${ }^{2}$ Biomass Conversion Divison, Research \\ Direction of Hydrocarbon Conversion, Mexican Institute of Petroleum, Mexico City, Mexico
}

Transition to a new energy low carbon pool requires the gradual replacing of fossil fuels with other cleaner energies and biofuels. In this work, the environmental impact of renewable diesel production using an attributional life cycle assessment was evaluated by considering five stages: palm plantation-culture-harvest, palm oil extraction, palm oil refining, green (renewable) diesel production, and biofuel use. The functional unit was established as $1.6 \times 10^{-2} \mathrm{~m}^{3}(13.13 \mathrm{~kg})$ of renewable diesel. The results show that the production of renewable diesel by Hydro-processed Esters and Fatty Acids is more environmentally friendly than fossil diesel production. In particular, the analysis showed that the $\mathrm{CO}_{2}$ emission decreases around $110 \%$ (i.e. mitigation occurred) compared with conventional diesel production. However, renewable diesel production has a relevant environmental impact in the human toxicity category due to the high consumption of agrochemicals during palm culture.

Keywords: environmental impact, green diesel, palm oil, life cycle (impact) assessment, biofuel

\section{INTRODUCTION}

The severe environmental problems related to the greenhouse effect and global warming have instigated a search for new and alternative energy sources to reduce the use of fuels derived from petroleum. One alternative is the use of biofuels, which are environmentally friendly (Guo et al., 2015). However, reliable tools are required to determine how friendly biofuels are for the environment. Life Cycle Assessment (LCA) is a methodology commonly used to evaluate the effect on the environment caused by industrial processes and services, from acquisition, manufacture, use, and maintenance of the raw material, until the final disposal of the product or service. Thus, LCA is one suitable tool for environmental decision-making (Curran, 2006).

Researchers have reported several LCA studies for biofuels in the last decades (Sampattagul et al., 2009; Ashnani et al., 2014; Piemonte et al., 2014; Uctug et al., 2017; Fortes et al., 2018; Parajuli et al., 2018; Tabatabaei et al., 2019; Chiriboga et al., 2020; Fridrihsone et al., 2020), showing environmental benefits because it can help moderate the impact of global warming and reduce dependence on fossil fuels. Parajuli et al. (Parajuli et al., 2018) described LCA within a biorefinery context, identifying that

Abbreviations: DCB, Dichlorobenzene; FFB, Fresh Fruit Bunches; FU, Functional Unit; GHG, Greenhouse Gas; ha, Hectare; HEFA, Hydro-processed Esters and Fatty Acids; LCA, Life Cycle Assessment; R11, Trichloromethane; RD, Renewable Diesel; T, Ton; ULSD, Ultra-Low Sulfur Diesel. 
the main effects of the system integration were in the reduction of Greenhouse Gas (GHG) emissions, fossil fuel consumption, eutrophication potential, and freshwater ecotoxicity, compared to a conventional mixed crop-livestock system, without the biogas conversion facility and the green biorefinery. However, it is necessary to move towards the large-scale replacement of conventional energy resources with renewable ones to turn to the circular economy model. Although some studies have claimed carbon neutrality, further studies assessing the environmental impact from cradle-to-grave are required to precisely determine the potential of any renewable fuel to absorb $\mathrm{CO}_{2}$.

The increase in "clean fuel" production focuses on mitigating pollutants from vehicle exhaust in response to the problems of petroleum-derived fuels. Biodiesel and renewable diesel (RD) are two biofuels that have been the subject of interest in recent years as potential substitutes for diesel fuel. Both biofuels use the same raw material (vegetable oils or animal fats). However, they have different chemical properties because their production occurs in different ways.

Biodiesel is a mixture of Fatty Acid Alkyl Esters (FAAEs). Biodiesel can be produced through the transesterification reaction between triacylglycerides and some alcohol (Peiró et al., 2010; Nanaki and Koroneos, 2012; Escobar et al., 2014; Carneiro et al., 2017; Fernandez et al., 2017; Alagumalai et al., 2020; Chamkalani et al., 2020; Seela et al., 2020; Jacob et al., 2021; Mukhopadhyay and Chakraborty, 2021). On the other hand, RD is a mixture of oxygen-free hydrocarbons, mainly alkanes, commonly being obtained by hydrotreating (Kalnes et al., 2007; Sotelo-Boyas et al., 2011; Ramírez-Verduzco and Hernández-Sánchez, 2020).

$\mathrm{RD}$ offers advantages over biodiesel. RD has a higher energy density and heating value than biodiesel because of the lack of oxygen atoms. $\mathrm{RD}$ also has a higher cetane number $(\sim 70)$ than biodiesel $(\sim 50)$. RD has storage stability and is compatible with petroleum diesel at any concentration (Kalnes et al., 2007; SoteloBoyas et al., 2011; Ramírez-Verduzco and Hernández-Sánchez, 2020). In addition, GHG emissions from RD are more than $80 \%$ lower than petroleum diesel and about $40 \%$ less than biodiesel (Kalnes et al., 2007). However, RD has two main disadvantages. First, the RD has poor cold flow properties [v.g. cloud point of 291.15 K (Ramírez-Verduzco and Hernández-Sánchez, 2020)], causing the formation of solids and deposits into the engines, especially in cold weather or winter seasons (Soo-Young, 2014; Kumar et al., 2018; Douvartzides et al., 2019). Secondly, RD reactions consume a significant amount of hydrogen (SoteloBoyas et al., 2011; Ramírez-Verduzco and Hernández-Sánchez, 2020).

Biofuels have to meet the regulatory requirements that guarantee quality and performance according to standards. Currently, the $\mathrm{RD}$ is still under research and development. $\mathrm{RD}$ has the inconvenience of flow cold properties, an aspect that needs to be improved. The best way to use this biofuel is by mixing it with ultra-low sulfur diesel (ULSD), which has a fossil origin.

In recent years hydrotreating has become a more common way to produce RD, known as Hydro-processed Esters and Fatty Acids (HEFA). This process involves decarboxylation, decarbonylation, and deoxygenation reactions (Kalnes et al., 2007; Sotelo-Boyas et al., 2011; Ramírez-Verduzco and Hernández-Sánchez, 2020). Some companies have been producing and commercializing RD. Such as Neste Oil, Petrobras, SK-Innovation, and UOP/Eni, through catalytic processes to carry out the hydrodeoxygenation of triacylglycerides.

Although efforts have been made to study the LCA of biodiesel (Peiró et al., 2010; Nanaki and Koroneos, 2012; Sandoval et al., 2014; Carneiro et al., 2017; Fernandez et al., 2017; Chamkalani et al., 2020; Mukhopadhyay and Chakraborty, 2021), according to the best of our knowledge, there are no LCA studies for RD production through palm oil hydrotreating. Considering that the production of biofuels is accompanied by their LCA is of vital importance to estimate emissions, this research postulates that it is possible to mitigate $\mathrm{GHG}$ emissions during the production and use of RD.

This study examines the environmental impact associated with the production and use of RD through LCA, a subject that is of interest to stakeholders from the petroleum industry, and other companies and researchers looking for green alternatives.

\section{MATERIALS AND METHODS}

An attributional LCA from cradle-to-grave of RD production and use in Mexico was performed according to ISO 14040 (ISO 14040, 2006) and ISO 14044 (ISO 14044, 2006), collecting the necessary input information from various sources such as companies, the administration of the Mexican government, and research centers (Kalnes et al., 2007; Mendez, 2010; Sandoval, 2011; Sandoval-Esquivez, 2011; Neste Oil Company, 2013; Nucci et al., 2014; Mesa and Piñeros, 2018; Sun et al., 2018). This information was requested and collected for all stages involved during the life cycle of RD (Figure 1).

\section{Functional Unit}

A functional unit (FU) of $1.6 \times 10^{-2} \mathrm{~m}^{3}(13.13 \mathrm{~kg})$ of $\mathrm{RD}$ was established based on the average production of African palm per hectare in Mexico (13.39 T/ha) (Ornelas-Ruiz-, 2021), considering that in each hectare planted, there is an average of 143 palm plants. Therefore, FU derives from the production of one of the 143 plants/ha.

\section{System Boundaries}

LCA boundaries were established from cradle-to-grave. The five stages selected were palm plantation-culture-harvest, palm oil extraction, palm oil refining, hydrodeoxygenation of refined palm oil, and RD production and use (Figure 1). The geographical area for the $\mathrm{RD}$ life cycle process was located at Veracruz state (for palm plantation-cultureharvest to palm oil extraction) and Mexico City (for palm refining and $\mathrm{RD}$ production). The environmental impact of infrastructure for every production stage was excluded in this work (Hernández, 2010). 


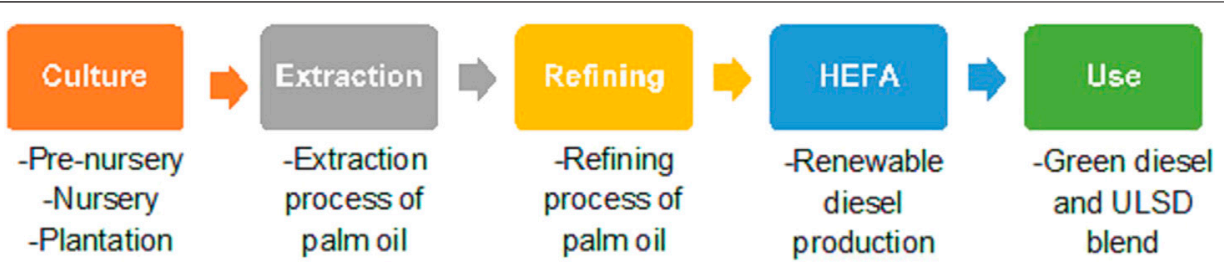

FIGURE 1 | Stages included in LCA of RD obtained by HEFA process.

TABLE 1 | Life cycle inventory.

\begin{tabular}{|c|c|c|c|c|c|c|}
\hline Stage & Inputs & Input value (g) & Outputs & Output value (g) & Energy (KW) & Water use $\left(\mathrm{m}^{3}\right)$ \\
\hline \multirow[t]{2}{*}{ Culture } & Fertilizers & $9,018.9$ & FFB & 93,630 & 2.8 & 378.108 \\
\hline & Pesticides & 345 & - & - & - & - \\
\hline \multirow[t]{5}{*}{ Palm oil extraction } & FFB & 93,630 & Palm oil & 18,726 & Vapor & 0.0936 \\
\hline & & & Sludge & 56,178 & 39.9 & \\
\hline & & & Empty clusters and husk & 27,152 & - & \\
\hline & & & Palmist oil & 1778 & Electricity & \\
\hline & & & Palm fiber & 12,171 & 2.3 & \\
\hline \multirow[t]{7}{*}{ Palm oil refining } & Palm oil & 18,726 & Refined palm oil & 15,916 & - & 0.0041 \\
\hline & & & Free fatty acid & 620 & Vapor & \\
\hline & Phosphoric acid & 17.9 & & & 0.16 & \\
\hline & & & Clay & 1740 & - & \\
\hline & & & Shell trace & 291 & Electricity & \\
\hline & Bentonite & 883 & & & 1.4 & \\
\hline & & & Gums & 589 & - & \\
\hline \multirow[t]{5}{*}{ HEFA } & Refined palm oil & 15,916 & $\mathrm{RD}$ & 13,130 & Vapor & 0.0068 \\
\hline & & & Water & 1,133 & 0.2 & \\
\hline & & & Propane & 818 & - & \\
\hline & Hydrogen & 337 & $\mathrm{CO}_{2}$ & 849 & Electricity & \\
\hline & & & $\mathrm{CO}$ & 276 & 1.4 & \\
\hline
\end{tabular}

\section{Assumptions}

In this work, various assumptions have been established to simplify the LCA. Due to a lack of information, the energy required to distribute water on the culture stage was not considered. For fresh fruit bunches (FFB), we based calculations on the supposition that they were transported by tractors (with up to $8 \mathrm{~T}$ of capacity) from plantations to the extraction plant. This would involve articulated truck (Euro 0-4 type) transport of crude palm oil with $27 \mathrm{~T}$ of capacity. The land-use change for palm plantations was not considered. A complete conversion of the biofuel hydrocarbon content into CO2 during combustion was assumed. Mass allocation methods for the assignment of co-product impacts were used. A scenario with data obtained from companies, Mexican government administration, or research centers was assumed. The location of the palm culture was presumed in Texistepec, Veracruz State. The origin of the palm oil was presumed to come from $\mathrm{FFB}$, performing its extraction in the plant known as Aceites de Palma SA de CV, which has industrial facilities and high capacity in Mexico, located at Acayucan (Veracruz State), $13.3 \mathrm{~km}$ away from the Texistepec. The palm refining and $\mathrm{RD}$ production was considered to occur in Mexico City. Pollutants from vehicle exhaust were assumed to be equal for $\mathrm{RD}$ and
ULSD. The $\mathrm{H}_{2}$ was presumed to come from the catalytic reforming process of a Mexican refinery, considering those with excess $\mathrm{H}_{2}$ capacity.

\section{Life Cycle Inventory}

Inputs (resources necessary for production) and outputs (products, co-products, emissions, and waste) were identified and quantified (Table 1) (Kalnes et al., 2007; Sandoval, 2011; Mendez, 2019; Sandoval-Esquivez, 2011; Neste Oil Company, 2013; Nucci et al., 2014; Mesa and Piñeros, 2018; Sun et al., 2018).

\section{Impact Categories}

The impact categories selected for the LCA that were simulated in this work are: global warming, acidification, eutrophication, ozone layer depletion, photochemical smog, and human toxicity. Those categories were selected based on their importance in terms of $\mathrm{C}$ fingerprint and GHG and previous reports of biofuels, and comparing them with fossil diesel and other biofuels.

\section{Software}

The LCA of RD was simulated in the CCalC2 software (V1.1) developed by the University of Manchester, which was selected due to its vast database and its user-friendly accessibility. Two 
TABLE 2 | Blue and green water use.

\begin{tabular}{|c|c|c|c|}
\hline Water use & Stage & Blue water ( $\left.\mathrm{m}^{3} / \mathrm{FU}\right)$ & Green water $\left(\mathrm{m}^{3} / \mathrm{FU}\right)$ \\
\hline Agricultural & Planting and harvesting & 108.57 & 269.43 \\
\hline Agricultural & Nursery & 0.102 & 0 \\
\hline Agricultural & Pre-nursery & 0.006 & 0 \\
\hline Process & Palm oil refining & 0.0041 & 0 \\
\hline Process & Green diesel production & 0.0068 & 0 \\
\hline Process & Palm oil extraction & 0.0936 & 0 \\
\hline Total & LCA for RD & $108.78 \mathrm{~m}^{3}$ & $269.43 \mathrm{~m}^{3}$ \\
\hline
\end{tabular}

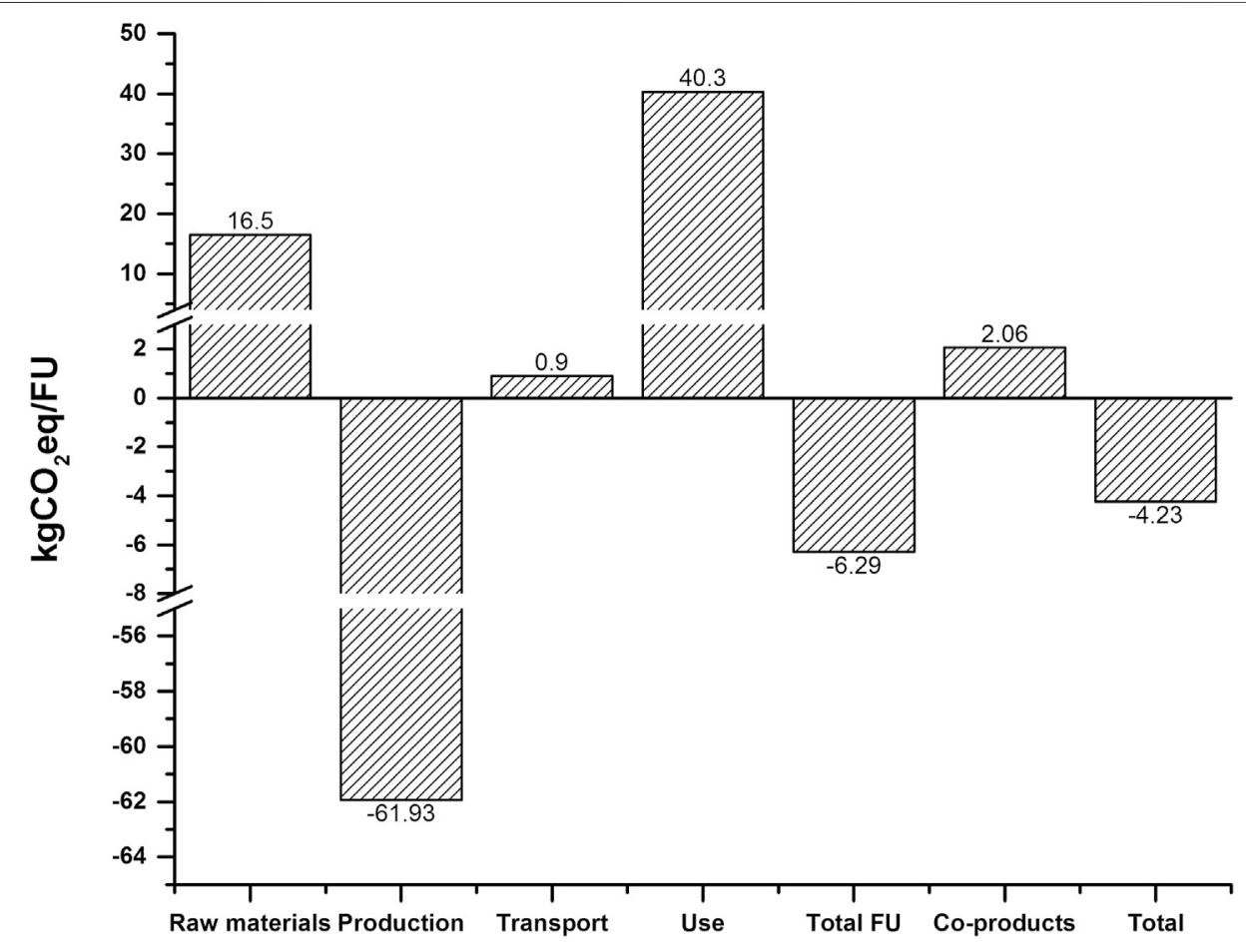

FIGURE 2 | Carbon footprint.

simulation runs of the LCA with bioethanol as a standard before addressing the $\mathrm{RD}$ were used to ensure the consistency and coherence of results with data reported in the literature (Mortimer et al., 2004).

\section{RESULTS AND DISCUSSION}

This section contains the main results found in this work for the environmental impact categories, comparing RD and RD-ULSD blend respect fossil diesel and other biofuels. It also describes the sensitivity analysis and alternative scenario proposals to improve the base case.

Before addressing the $\mathrm{RD}$, the LCA of bioethanol was simulated from two different sources, sugar beet and wheat. GHG emissions of 43.9 and $49.1 \mathrm{gCO}_{2}$ eq./MJ were obtained with the CCaLC2 software, respectively. Those values were close to the $39 \pm 3$ and $44 \pm 3 \mathrm{gCO}_{2}$ eq./MJ reported by Mortimer et al. (2004).
In terms of $\mathrm{RD}$, our simulation shows that the water needed to produce $1.6 \times 10^{-2} \mathrm{~m}^{3}$ of RD in Mexico was $378.2 \mathrm{~m}^{3}$ (Table 2), using more than $99 \%$ of this water for agriculture in the palm plantation and $0.1045 \mathrm{~m}^{3}$ during the processing of the palm fruit until obtaining the RD.

Palm culture has high water requirements for good development, more than $150 \mathrm{~mm}$ per month. The water footprint measured with the Pfister method (40) is $82.2 \mathrm{~m}^{3}$, derived from the multiplication of the total blue water used in the life cycle by the corresponding water stress index for each country. Palm culture has high water requirements for good development, more than $150 \mathrm{~mm}$ per month.

The water footprint for $\mathrm{RD}$ production is equivalent to $0.142 \mathrm{~m}^{3} / \mathrm{MJ}$, a relevant impact compared with other biofuels. For example, some studies performed in the United States have shown that the water footprint of rapeseed biodiesel and beet bioethanol is $6 \times 10^{-2}$ and $2 \times 10^{-2} \mathrm{~m}^{3} / \mathrm{MJ}$, respectively (GerbensLeenes and Hoekstra, 2010). 


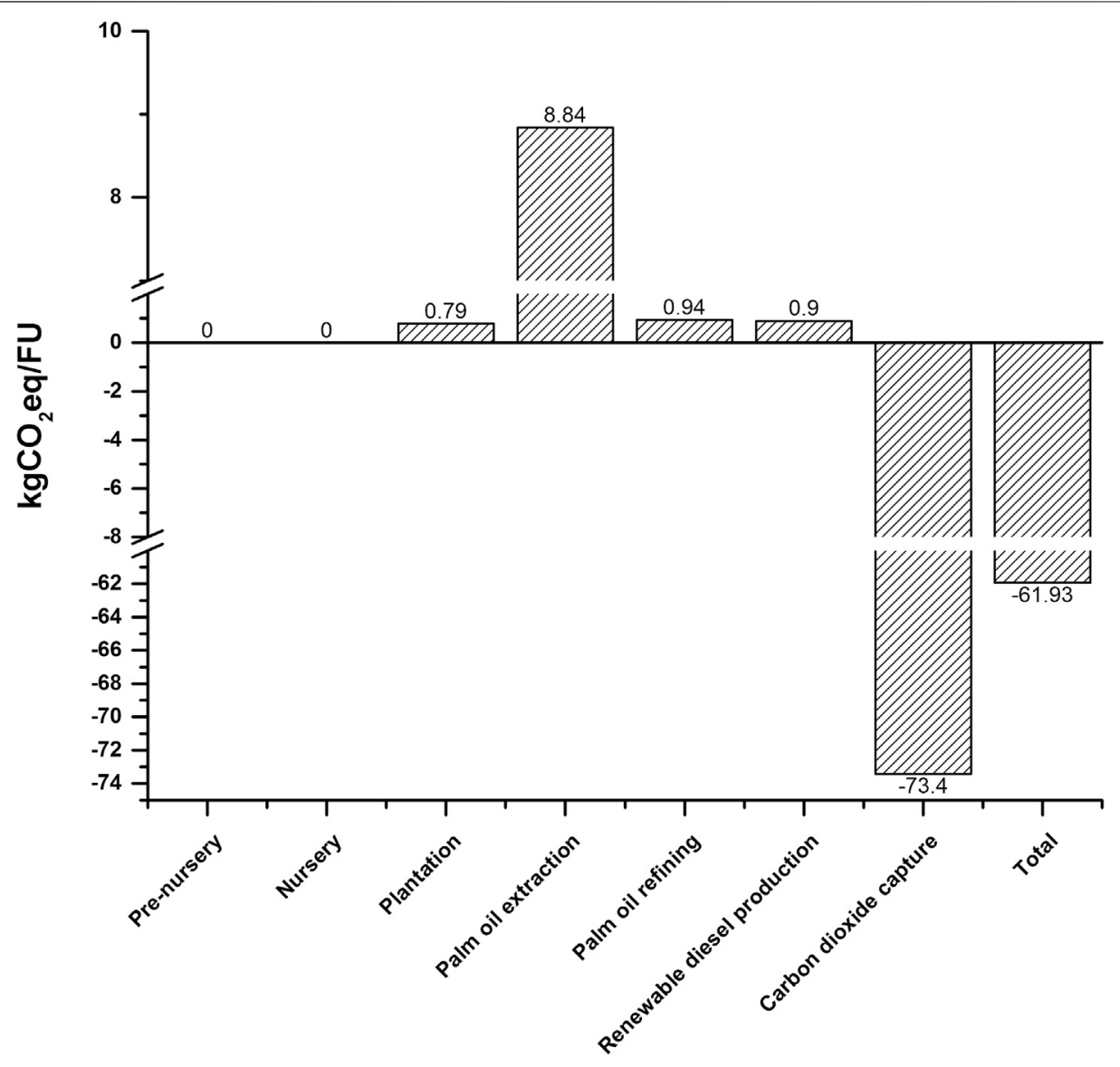

FIGURE 3 | Carbon footprint for the production stages.

\section{Environmental Impacts of RD Production}

Regarding global warming, Figure 2 shows the carbon footprint. The highest emissions are mainly due to fuel combustion and palm oil processing. The last category includes everything necessary to obtain each material in the system, such as extraction/production, energy, and emissions, among others.

Within the production process shown in Figure 3, the stage with the highest generation of emissions is palm oil extraction, caused by the large amount of energy used in the production of steam required for the palm fruit treatment.

There is a total emission of $-4.23 \mathrm{~kg}$ of $\mathrm{CO}_{2}$, which corresponds to $-7.32 \mathrm{gCO}_{2} \mathrm{eq} / \mathrm{MJ}$ for $\mathrm{RD}$ production. $108.3 \%$ of reduction in $\mathrm{CO}_{2} / \mathrm{FU}$ was obtained when our results are compared with the average emissions from extraction and use of fossil diesel (87.54 $\mathrm{gCO}_{2} \mathrm{eq} / \mathrm{MJ}$ ) (Eriksson and Ahlgren, 2013).

The acidification potential for $\mathrm{RD}$ production is $229 \mathrm{gSO}_{2} \mathrm{eq} /$ $\mathrm{FU}$ (Figure 4). Considering that biofuel has zero sulfur content, it does not generate $\mathrm{SO}_{2}$ emissions during its use. The emissions of this impact (17.4\%) occur during the production of the required energy for oil extraction, refining, and RD production. The rest of the emissions are mainly related to palm culture supplies, like the triple superphosphate, which contributes to $\left.128 \mathrm{gSO}_{2} \mathrm{eq} / \mathrm{FU}\right)$.

Regarding eutrophication, Palm culture requires large amounts of fertilizers, mainly phosphorus-, and nitrogen- based, which are used at least twice a year during plantation, increasing the amounts of fertilizer in the last years of palm life when the production curve decreases. The phosphate equivalent emissions generated in the RD production are mostly (>95\%) derived from the use of fertilizers during the culture stage within the production chain (Figure 4).

Concerning ozone layer depletion, the amount of trichlorofluoromethane (R11) emitted is $1.75 \mathrm{mg}$ in the production of $1.6 \times 10^{-2} \mathrm{~m}^{3}$ of RD (Figure 4). At least $95 \%$ of the ozone layer depletion potential is related to the procurement/ production of raw materials, while the remainder is related to energy production and transportation.

Regarding photochemical smog, the RD production causes $12.1 \mathrm{~g}$ of ethene eq (Figure 4). $27.5 \%$ of the emissions come from the generation of energy (electricity and steam) used in the production stages (oil extraction, oil refining, and oil conversion by the HEFA process). $69.4 \%$ of emissions occur during raw material production. Triple superphosphate is the principal cause for $42.3 \%$ of the emissions in the photochemical smog category.

Human toxicity is the most significant impact evaluated in $\mathrm{RD}$ production, reaching $36.8 \mathrm{~kg}$ of Dichlorobenzene (DCB) eq (Figure 4). Palm production (pre-nursery, nursery, and culture) generates around $54.5 \%$ emissions of the total due to 


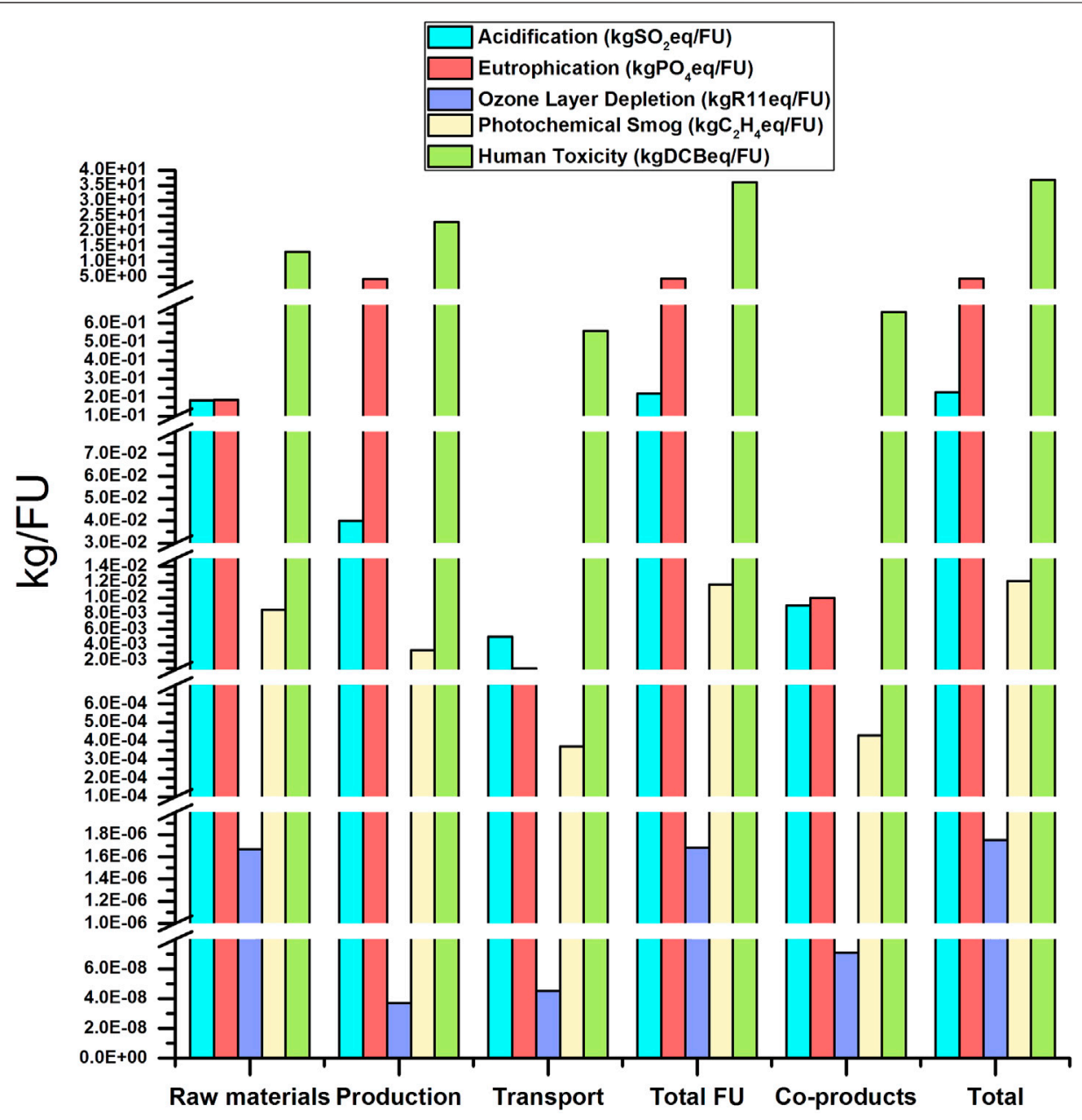

FIGURE 4 | Emissions on each impact category.

TABLE 3 | Emissions in the impact categories.

\begin{tabular}{lccccc}
\hline Impact category & Units & Diesel $^{\mathbf{a}}$ & B100 & ME50 & RD \\
\hline Global warming & $\mathrm{gCO}_{2} \mathrm{eq} / \mathrm{MJ}$ & 79.93 & 61.35 & 68.56 & -7.32 \\
Acidification & $\mathrm{gSO}_{2} \mathrm{eq} / \mathrm{MJ}$ & 0.547 & 0.7 & 0.476 & 0.396 \\
Eutrophication & $\mathrm{gPO}_{4} \mathrm{eq} / \mathrm{MJ}$ & 0.127 & 1.78 & 0.331 & 7.67 \\
Ozone layer depletion & $\mathrm{mgCFC}^{-11 \mathrm{eq} / \mathrm{MJ}}$ & 0.012 & 0.006 & 0.007 & 0.003 \\
Photochemical smog & $\mathrm{gC}_{2} \mathrm{H}_{4} \mathrm{eq} / \mathrm{MJ}$ & 0.033 & - & - & 0.021 \\
Human toxicity & $\mathrm{g}^{1,4-\mathrm{DCBeq} / \mathrm{MJ}}$ & 7.37 & 64.11 & 9.63 & 63.67
\end{tabular}

${ }^{a}$ Data from Ecoinvent 2.1.

the use of pesticides, insecticides, and herbicides during the culture stage, such as carbofuran, glyphosate, benomyl, and mainly methyl bromide.

The oil extraction, oil refining, and $\mathrm{RD}$ production process contribute $8 \%$ of the total emissions. This impact mainly comes from the generation of energy necessary in the above three stages.

Obtaining raw materials is of particular note, accounting for $35.9 \%$ of total emissions. The fertilizers generate a relevant environmental impact in which triple superphosphate is again the pollutant source that contributes the most to human toxicity potential.

\section{Comparison of the Environmental Impact of RD Production and Use With Biodiesel and Fossil Diesel}

$\mathrm{RD}$ presents a notable decrease to conventional diesel in global warming, ozone layer depletion, photochemical smog, 109.1, 75, and $36.4 \%$ (Table 3). It also exhibits a competitive environmental advantage regarding the other two biofuels, biodiesel at $100 \%$ (B100), and RD by microemulsion at $50 \%$ of mixture in volume (ME50) (Arpornpong et al., 2015).

Regarding acidification potential, $\mathrm{RD}$ has about a $27.6 \%$ reduction in emissions than conventional diesel. $\mathrm{RD}$ has a minor impact compared to ME50 (a second-generation biofuel) and B100 in this category.

For the eutrophication and human toxicity potential categories, RD has a significant environmental impact, about 60 and 8.6 times more than conventional diesel, respectively. 
TABLE 4 | Effect of use of RD-ULSD blend on emissions.

Impact category

Global warming

Acidification

Eutrophication

Ozone layer depletion

Photochemical smog

Human toxicity
Units

$\mathrm{gCO}_{2} \mathrm{eg} / \mathrm{MJ}$

$\mathrm{gSO}_{2} \mathrm{eq} / \mathrm{MJ}$

$\mathrm{gPO}_{4}$ eq/MJ

mgR11eq/MJ

$\mathrm{gC}_{2} \mathrm{H}_{4} / \mathrm{MJ}$

g1,4-DCBeq/MJ
Blend at $25 \%$ of $\mathrm{RD}$ and $\mathbf{7 5} \%$ of ULSD in volume

63.83

0.51

2.01

0.01

0.03

21.44
Environmental impact in eutrophication principally occurs in the plantation-culture-harvest stage.

The use of inorganic fertilizers, such as triple superphosphate during palm culture, represents a common practice in Mexico. This practice significantly increases eutrophication. Additionally, the use of herbicides and pesticides in Mexico has generated toxicity problems, such as respiratory diseases in people and contamination of aquifers and soil.

Other substances that are also harmful to health and are highly toxic include methyl bromide and carbofuran, which are commonly used as agrochemicals during palm culture by farmers in Mexico.

\section{Emissions Derived From the RD-ULSD Blend}

For this study, the chemical and yield characteristics of an RD synthesized by HEFA were considered, the details of this process are reported in previous work (Ramírez-Verduzco and Hernández-Sánchez, 2020) and described briefly below.

$\mathrm{RD}$ was produced in a reactor using a $\mathrm{NiMo} / \gamma-\mathrm{Al}_{2} \mathrm{O}_{3}$ catalyst at the following operating conditions, such as temperature, pressure, liquid hourly space velocity (LHSV), and $\mathrm{H}_{2}$ /oil ratio equal to $613 \mathrm{~K}, 4,903 \mathrm{kPa}, 1.0 \mathrm{~h}^{-1}$, and $935 \mathrm{std} . \mathrm{m}^{3} / \mathrm{m}^{3}$ respectively. For the LCA, the use of $\mathrm{H}_{2}$ was assumed to come from the catalytic reforming process of a Mexican refinery, considering those with excess $\mathrm{H}_{2}$ capacity.

The HEFA process consists of two reaction steps. First, the obtention of diglycerides occurs, including monoglycerides, carboxylic acids, and propane. This happens through the hydrogenation of double bonds and $\mathrm{C}-\mathrm{O}$ bond cleavage. Second, carboxylic acids convert into final products through three parallel reactions (deoxygenation, decarboxylation, and decarbonylation). The products are alkanes water, $\mathrm{CO}_{2}$, and $\mathrm{CO}$.

Although RD obtained by HEFA met most of the chemical and physical characteristics required by the Mexican standard for diesel (Official Mexican Standard NOM-016-CRE-2016), the RD did not meet the regulatory requirement for low-temperature flow properties (pour and cloud points). The Mexican standard for the pour point from March to October requires a maximum of $273 \mathrm{~K}$, while from November to February, a maximum of $268 \mathrm{~K}$. The cloud point depends on the temperature conditions for proper diesel distribution. However, Mexico's average lowest temperature is around $272.4 \mathrm{~K}$. Our experimental measurements for the pour and cloud points were 288 and $291 \mathrm{~K}$, respectively. Therefore, we do not recommend the direct use of $\mathrm{RD}$ in engines for cold regions. Instead, we propose mixing RD with ULSD (<10 ppm S). We performed a study on the establishment of the adequate mixing percentage and use this mixture to complement our LCA and ensure proper engine operation. We obtained a mixture that ensures regulatory compliance for the flow properties at low temperature is 25 and $75 \%$ by volume of $\mathrm{RD}$ and ULSD, respectively. Because this mixture had a pour point of $267.4 \mathrm{~K}$ and a cloud point of 269.3 K, those values comply satisfactorily with the Mexican standard. Then we estimated the environmental impact for the blend by simulating the LCA (Table 4). According to our study, a mixture of $\mathrm{RD}$ with Mexican ULSD would reduce GHG emissions by $27 \%$ over single fossil diesel. However, the blend increases the impact in eutrophication $(\sim 16$ times) and human toxicity ( $\sim 3$ times) more than single fossil diesel.

\section{Sensitivity Analysis}

Through sensitivity analysis, we used inputs with uncertainty to verify the variability of the results in stages or specific data and detect ranges for which the simulated information is or not the desired outcome (Curran, 2015).

We performed the sensitivity analysis by considering four parameters, energy use, palm harvest efficiency, oil refining yield, and HEFA yield. Table 5 shows the results of this analysis. The simulations carried out with a $20 \%$ variation in energy use show that, except for the eutrophication potential (which remains constant), all categories are affected to a greater or lesser extent as the amount of energy used decreases, the different impacts also decrease. The simulations carried out with a $20 \%$ variation in the oil palm harvest efficiency reveal that as efficiency increases, emissions also increase in the global warming category and emissions decrease for the other categories of environmental impact. The simulations carried out with a $10 \%$ variation in the oil refining yield reveal that as it increases, the environmental impact on the global warming category also increases, while the rest decrease. The simulations carried out with a $10 \%$ variation in the HEFA yield reveal that as it is higher, the environmental impact on the global warming category also increases, while the rest decrease.

From the above, we notice an advantage of renewable energy use in the life cycle through sensitivity analysis. In contrast, generating power by burning fossil fuels is not a recommended option since it increases emissions in five impact categories. Only emissions in the eutrophication category remain constant.

The sensitivity analysis also indicates that the plantation efficiency and production yields (mainly in palm oil refining and the HEFA process) could modify the impact depending on 
TABLE 5 | Effect of production parameters on emissions.

\begin{tabular}{|c|c|c|c|c|}
\hline Impact category & Energy use $(-/+20 \%)$ & Palm efficiency $(-/+20 \%)$ & Oil refining yield $(-/+10 \%)$ & HEFA yield $(-/+10 \%)$ \\
\hline Global warming (gCO $2 \mathrm{eq} / \mathrm{MJ})$ & $-12.1--1.8$ & $-1.3-9.8$ & $-16.8-0.1$ & $-16--0.37$ \\
\hline Acidification $\left(\mathrm{gSO}_{2} \mathrm{eq} / \mathrm{MJ}\right)$ & $0.38-0.42$ & $0.35-0.47$ & $0.36-0.44$ & $0.36-0.44$ \\
\hline Eutrophication $\left(\mathrm{gPO}_{4} \mathrm{eq} / \mathrm{MJ}\right)$ & 7.7 & $6.4-9.6$ & $6.9-8.5$ & $6.9-8.5$ \\
\hline Ozone layer depletion (mgR11eq/MJ) & $2.9 \times 10^{-3}-3.2 \times 10^{-3}$ & $2.6 \times 10^{-3}-3.6 \times 10^{-3}$ & $2.7 \times 10^{-3}-3.3 \times 10^{-3}$ & $2.7 \times 10^{-3}-3.3 \times 10^{-3}$ \\
\hline Photochemical smog $\left(\mathrm{gC}_{2} \mathrm{H}_{4} \mathrm{eq} / \mathrm{MJ}\right)$ & $1.9 \times 10^{-2}-2.2 \times 10^{-2}$ & $1.9 \times 10^{-2}-2.4 \times 10^{-2}$ & $1.9 \times 10^{-2}-2.3 \times 10^{-2}$ & $1.9 \times 10^{-2}-2.3 \times 10^{-2}$ \\
\hline Human toxicity (g1,4-DCBeq/MJ) & $62.7-65.5$ & $54.3-77.9$ & $58.1-70.6$ & $57.9-70.8$ \\
\hline
\end{tabular}

the situation. As an illustration, if we could get better efficiency and production yields, the environmental impact will decrease in five out of the six categories (excluding global warming having an inverse behavior). Taking this into account, changes in cultivation practices are relevant, to achieve more palm fruit per hectare and improve the refining palm oil and HEFA process, enabling a higher yield during both stages.

\section{Alternative Scenarios as Better Practices}

The goal for the alternative scenarios is to identify opportunity areas in the value chain of $\mathrm{RD}$ production. This indicates how to achieve a reduction in environmental impact in the life cycle by modifying the base scenario and the results of the improvement proposals are described here.

The substitution of conventional pesticides by biopesticides contributes to having a notorious reduction of the emissions concerning the baseline scenario. The emissions decreased 60 and $10 \%$ in the categories of human toxicity and ozone layer depletion. While for global warming, photochemical smog and acidification decreased 5\%. In terms of the change of location, we propose an alternate scenario where the palm plantation and oil extraction were in Acapetahua, Chiapas. This location has ideal weather for palm production. It also has an oil extraction plant of the company OLEO SUR located in the state of Chiapas as the principal palm producer in Mexico. Oil refining occurs in the same company as the extraction in Coatzacoalcos-Veracruz. The $\mathrm{RD}$ production is now in Minatitlán, Veracruz. The results show that the change of location between the stages of the process generates a slight increase in global warming, acidification, human toxicity, and the rest of the categories remain constant. This is because the transport of inputs and by-products is higher. For the mature plantation, the LCA of RD has an environmental impact generated from palm culture until RD production.

The palm begins to produce fruit about two years after sowing. This simulation represents the emissions generated for a mature plantation, not considering the environmental impact of prenursery and nursery. It is worth mentioning that the plantation palm is mature about six years after transplanting palm. Mature crops reduce the potential for emissions in all the categories evaluated, highlighting $66.6 \%$ in water footprint and $21.5 \%$ in human toxicity. In the case of the $\mathrm{CO}_{2}$ capture, we assume that the carbon emitted by $\mathrm{RD}$ combustion comes from biomass, which captures $\mathrm{CO}_{2}$ for the biomass itself, therefore, global warming is the only modified category. Although it increases considerably in the baseline scenario, it presents a reduction of $42.7 \%$ compared to fossil diesel.

\section{CONCLUSION}

Considering that the production of biofuels accompanied by their LCA is of vital importance to reduce emissions, this research demonstrated that it is possible to mitigate the amount of GHG emissions during the production and use of $\mathrm{RD}$.

The LCA of RD demonstrated that biofuel significantly reduces GHG emissions than its fossil counterpart by about $110 \%$.

$\mathrm{RD}$ production has lower emissions than conventional diesel. There is a low environmental impact in terms of acidification, ozone layer depletion, and photochemical smog. In both cases, there was a high impact on human toxicity and eutrophication.

Palm culture has high water requirements for good development, more than $150 \mathrm{~mm}$ per month, causing a higher water footprint than other biofuels.

$\mathrm{RD}$ has poor cold flow properties (pour and cloud point), making it difficult to use in cold regions. It is, therefore, necessary to mix it with ULSD to comply with fuel quality regulations. An adequate mixing percentage may vary depending on the average ambient temperature conditions and standards.

Raw material obtention has a higher environmental impact, mainly due to fertilizers and hydrogen. Selecting adequate supplies is relevant to reduce environmental impact.

Fossil fuels account for $80 \%$ of energy use, which affects every category evaluated. We recommend the use of renewable energy to reduce impact during $\mathrm{RD}$ production.

The efficiency of palm plantations is a factor that considerably affects the impact potentials. Soil studies, modification of fertilization techniques, and replacement of agrochemicals with bioproducts are some methods of improving plantation performance and significantly reducing environmental impact.

The environmental impact caused by $\mathrm{RD}$ production is higher in the first years of palm culture, decreasing at the mature culture stage.

$\mathrm{RD}$ could be a sustainable option to reduce the use of conventional fossil diesel. However, our study has limitations imposed by the technology used in Mexico for the plantationculture-harvest of palm and the maturity level of the $\mathrm{RD}$ production technology.

$\mathrm{RD}$ production technologies are still in development, being less mature than diesel hydrodesulfurization processes in terms of producing fossil diesel. Therefore, future work should focus on monitoring the evolution of RD production technology through LCA studies. Some examples of technological challenges are the following: Research for ecological agriculture, biopesticides, and bio-stimulants. The development of new active catalysts will 
allow for the use of less severe operating conditions for the RD production process. Use renewable sources for the energy production and $\mathrm{H}_{2}$ required in the $\mathrm{RD}$ production process, and it is necessary to ensure optimal use of by-products and waste such as light gases, $\mathrm{CO}_{2}$, and $\mathrm{CO}$.

\section{DATA AVAILABILITY STATEMENT}

The original contributions presented in the study are included in the article/Supplementary Material, further inquiries can be directed to the corresponding authors.

\section{AUTHOR CONTRIBUTIONS}

AA-A collected the inventory data and performed the LCA simulation. LR-V translated and edited the document and made graphics of figures 2-4 with the Origin software,

\section{REFERENCES}

Alagumalai, A., Mathimani, T., Pugazhendhi, A., Atabani, A. E., Brindhadevi, K., and Duc Canh, N. (2020). Experimental Insight into Co-combustion Characteristics of Oxygenated Biofuels in Modified DICI Engine. Fuel 278, 118303. doi:10.1016/j.fuel.2020.118303

Arpornpong, N., Sabatini, D. A., Khaodhiar, S., and Charoensaeng, A. (2015). Life Cycle Assessment of palm Oil Microemulsion-Based Biofuel. Int. J. Life Cycle Assess. 20, 913-926. doi:10.1007/s11367-015-0888-5

Ashnani, M. H. M., Johari, A., Hashim, H., and has ani, E. (2014). Life Cycle Assessment of palm Oil Biodiesel Production in Malaysia. Appl. Mechanic. Mater. 465-466, 1080-1108. doi:10.4028/www.scientific.net/AMM.465466.1080

Carneiro, M. L. N. M., Pradelle, F., Braga, S. L., Gomes, M. S. P., Martins, A. R. F. A., Turkovics, F., et al. (2017). Potential of Biofuels from Algae: Comparison with Fossil Fuels, Ethanol and Biodiesel in Europe and Brazil through Life Cycle Assessment (LCA). Renew. Sustain. Energ. Rev. 73, 632-653. doi:10.1016/ j.rser.2017.01.152

Chamkalani, A., Zendehboudi, S., Rezaei, N., and Hawboldt, K. (2020). A Critical Review on Life Cycle Analysis of Algae Biodiesel: Current Challenges and Future Prospects. Renew. Sustain. Energ. Rev. 134, 110143. doi:10.1016/j.rser.2020.110143

Chiriboga, G., De La Rosa, A., Molina, C., Velarde, S., and Carvajal, G. (2020). Energy Return on Investment (EROI) and Life Cycle Analysis (LCA) of Biofuels in Ecuador. Heliyon 6, 1-11. doi:10.1016/j.heliyon.2020.e04213

Curran, M. A. (2006). Data from: Scientific Applications International Corporation. Life Cycle Assessment: Principles and Practice. Cincinnati, OH: U.S. Environmental Protection Agency. (EPA), EPA/600/R-06/060. Available at: https://cfpub.epa. gov/si/si_public_record_report.cfm?Lab=NRMRL\&dirEntryId=155087

Curran, M. A. (2015). Life Cycle Assessment Student Handbook. A Guide for Environmentally Sustainable Products. USA: HardcoverScrivener Publishing LLC. John Wiley \& Sons.

Neste Oil Company (2013). Data from: NExBTL Renewable Diesel Singapore Plant, Technical Report. Singapore: Neste Proprietary Publication. Available at: https://www.neste.com/about-neste (Accessed December 12, 2020).

Douvartzides, S. L., Charisiou, N. D., Papageridis, K. N., and Goula, M. A. (2019). Green Diesel: Biomass Feedstocks, Production Technologies, Catalytic Research, Fuel Properties and Performance in Compression Ignition Internal Combustion Engines. Energies 809, 1-42. doi:10.3390/en12050809

Eriksson, M., and Ahlgren, S. (2013). Data from: LCAs of Petrol and Diesel, Institutionen for Energi Och Teknik. Southampton: Swedish University of Agricultural Sciences. Available at: https://pub.epsilon.slu.se/10424/17/ ahlgren_s_and_eriksson_m_130529.pdf (Accessed December 12, 2020). reviewed results of HEFA process. MA-A conceptualized and supervised the work, reviewed the results of LCA and reviewed and edited the document.

\section{FUNDING}

CONACyT and Energy Secretary financed the research through CEMIE-Bio. AA-A received a scholarship from CONACyT for post-graduate studies.

\section{ACKNOWLEDGMENTS}

We carried out this work as part of the Y.61023 project Clúster CEMIE-Bio Bioturbosina. The authors thank the Instituto Mexicano del Petróleo for making the conclusion of this work possible. AA-A acknowledges an M. Sc. Scholarship from CONACYT.

Escobar, N., Ribal, J., Clemente, G., and Sanjuán, N. (2014). Consequential LCA of Two Alternative Systems for Biodiesel Consumption in Spain, Considering Uncertainty. J. Clean. Prod. 79, 61-73. doi:10.1016/j.jclepro.2014.05.065

Fernandez, I. A. P., Liu, D. H., and Zhao, J. (2017). LCA Studies Comparing Alkaline and Immobilized Enzyme Catalyst Processes for Biodiesel Production under Brazilian Conditions. Resour. Conserv. Recy. 119, 117-127. doi:10.1016/ j.resconrec.2016.05.009

Fortes, S., Costa, M., Queiroz, L., and Jacob-Lopes, E. (2018). Life Cycle Assessment (LCA) of Third-Generation Biodiesel Produced Heterotrophically by Phormidium Autumnale. Open Biotech. J. 12, 270-281. doi:10.2174/ 1874070701812010270

Fridrihsone, A., Romagnoli, F., and Cabulis, U. (2020). Environmental Life Cycle Assessment of Rapeseed and Rapeseed Oil Produced in Northern Europe: A Latvian Case Study. Sustain 12, 1-21. doi:10.3390/su12145699

Gerbens-Leenes, W., and Hoekstra, A. Y. (2010). Data from: Burning Water: the Water Footprint of Biofuel-Based Transport. Available at: https://research. utwente.nl/en/publications/burning-water-the-water-footprint-of-biofuel-basedtransport. Groningen: UNESCO-IHE. Research Report Series No. 44.

Guo, M., Song, W., and Buhain, J. (2015). Bioenergy and Biofuels: History, Status, and Perspective. Renew. Sustain. Energ. Rev. 42, 712-725. doi:10.1016/ j.rser.2014.10.013

Hernández, F. (2010). Análisis técnico, económico y medioambiental de los potenciales sustitutos de los hidrocarburos en el mercado español de los combustibles para automoción. Madrid, Spain: Universidad Politécnica de Madrid. [dissertation/Ph.D.'s thesis]. [España].

ISO 14040 (2006). Environmental Management - Life Cycle Assessment-Principles and Framework. Available at: https://www.iso.org/standard/37456.html (Accessed December 12, 2020).

ISO 14044 (2006). Environmental Management - Life Cycle Assessment Requirements and Guidelines. Available at: https://www.iso.org/standard/ 38498.html (Accessed December 12, 2020).

Jacob, A., Ashok, B., Alagumalai, A., Chyuan, O. H., and Le, P. T. K. (2021). Critical Review on Third Generation Micro Algae Biodiesel Production and its Feasibility as Future Bioenergy for IC Engine Applications. Energ. Convers. Manage. 228 (2), 113655. doi:10.1016/j.enconman.2020.113655

Kalnes, T., Marker, T., and Shonnard, D. R. (2007). Green Diesel: a Second Generation Biofuel. Int. J. Chem. React. Eng. 5 (1). doi:10.2202/1542-6580.1554

Kumar, V., Sindhu, R. K., and Kumar, S. (2018). Comparative Analysis of green Diesel versus Petro-Diesel in Compression Ignition Engine. Biosci. Biotech. Res. Comm. 11, 128-135. doi:10.21786/bbrc/11.1/18

Méndez, C. (2019). Refinación de aceite crudo de palma acondicionado como carga a un proceso de hidrodesoxigenación (HDO). Mexico City: Instituto Mexicano del Petróleo. [dissertation/master's thesis]. [México]. 
Mesa, H., and Piñeros, L. (2018). Fabricación y montaje de los equipos para una planta extractora de aceite de palma. Colombia: Universidad Piloto de Colombia. [dissertation/master's thesis]. [Colombia].

Mortimer, N. D., Elsayed, M. A., and Horne, R. E. (2004). Energy and Greenhouse Gas Emissions for Bioethanol Production from Wheat Grain and Sugar Beet. January: Final Report for British Sugar plc. Report No. 23/1.

Mukhopadhyay, P., and Chakraborty, R. (2021). LCA of Sustainable Biodiesel Production from Fried Borassus Flabellifer Oil in Energy-Proficient Reactors: Impact Assessment of Multi Fuel-Additives on Pour point, NOx and Engine Performance. Sustainable Energ. Tech. Assessments 44, 100994. doi:10.1016/ j.seta.2021.100994

Nanaki, E. A., and Koroneos, C. J. (2012). Comparative LCA of the Use of Biodiesel, Diesel and Gasoline for Transportation. J. Clean. Prod. 20 (1), 14-19. doi:10.1016/j.jclepro.2011.07.026

Nucci, B., Puccini, M., Pelagagge, L., Vitolo, S., and Nicolella, C. (2014). Improving the Environmental Performance of Vegetable Oil Processing through LCA. J. Clean. Prod. 64, 310-322. doi:10.1016/j.jclepro.2013.07.049

Ornelas-Ruiz-, P. (2021). Data from: Servicio de Información Agroalimentaria y Pesquera, Gobierno de México. Available at: https://www.gob.mx/siap (Accessed December 12, 2020).

Parajuli, R., Dalgaard, T., and Birkved, M. (2018). Can Farmers Mitigate Environmental Impacts through Combined Production of Food, Fuel and Feed? A Consequential Life Cycle Assessment of Integrated Mixed CropLivestock System with a green Biorefinery. Sci. Total Environ. 619-620, 127-143. doi:10.1016/j.scitotenv.2017.11.082

Peiró, L. T., Lombardi, L., Méndez, G. V., and Durany, X. G. (2010). Life Cycle Assessment (LCA) and Exergetic Life Cycle Assessment (ELCA) of the Production of Biodiesel from Used Cooking Oil (UCO). Energy 35 (2), 889-893. doi:10.1016/j.energy.2009.07.013

Pfister, S., Koehler, A., and Hellweg, S. (2009). Assessing the Environmental Impacts of Freshwater Consumption in LCA. Environ. Sci. Technol. 43, 4098-4104. doi:10.1021/es802423e

Piemonte, V., Di Paola, L., and Russo, V. (2014). An LCA Study on Feedstocks and Processes for Biofuels Production. Chem. Eng. Trans. 37, 517-522.

Ramírez-Verduzco, L. F., and Hernández-Sánchez, M. J. (2020). Blends of Green Diesel (Synthetized from Palm Oil) and Petroleum Diesel: A Study on the Density and Viscosity. Bioenerg. Res. In press. doi:10.1007/s12155-020-10183-y

Sampattagul, S., Suttibut, C., and Kiatsiriroat, T. (2009). LCA/LCC of Jatropha Biodiesel Production in Thailand. Int. J. Renew. Energ. 4, 33-42. doi:10.14456/iire.2009.1

Sandoval, A. (2011). Data from: Paquete tecnológico palma de aceite: Establecimiento y Mantenimiento. Available at: https://franciscodelgado. tripod.com/palmamexico.pdfSAGARPA. Centro de Investigación Regional Pacífico Sur

Sandoval-Esquivez, A. (2011). Data from: Paquete tecnológico palma de aceite (Elaeis guinnensis jacq.) Producción. SAGARPA. Centro de Investigación Regional
Pacífico Sur https://docplayer.es/10763640-Produccion-de-planta-paquetetecnologico-palma-de-aceite-elaeis-guinnensis-jacq-paquete-tecnologico-palmade-aceite.html.

Seela, C. R., AlagumalaiPugazhendhi, A. A., and Pugazhendhi, A. (2020). Evaluating the Feasibility of Diethyl Ether and Isobutanol Added Jatropha Curcas Biodiesel as Environmentally Friendly Fuel Blends. Sustain. Chem. Pharm. 18 (7), 100340. doi:10.1016/j.scp.2020.100340

Soo-Young, N. (2014). Application of Hydrotreated Vegetable Oil from Triglyceride Based Biomass to CI Engines - A Review. Fuel 115, 88-96. doi:10.1016/j.fuel.2013.07.001

Sotelo-Boyas, R., Liu, Y., and Minowa, T. (2011). Renewable Diesel Production from the Hydrotreating of Rapeseed Oil with Pt/Zeolite and NiMo/Al2O3 Catalyst. Eng. Chem. Res. 50, 2791-2799. doi:10.1021/ie100824d

Sun, P., Elgowainy, A., Wang, M., Han, J., and Henderson, R. J. (2018). Estimation of U.S. Refinery Water Consumption and Allocation to Refinery Products. Fuel 221, 542-557. doi:10.1016/j.fuel.2017.07.089

Tabatabaei, M., Aghbashlo, M., Najafi, B., Hosseinzadeh-Bandbafha, H., Faizollahzadeh Ardabili, S., Akbarian, E., et al. (2019). Environmental Impact Assessment of the Mechanical Shaft Work Produced in a Diesel Engine Running on Diesel/biodiesel Blends Containing GlycerolDerived Triacetin. J. Clean. Prod. 223, 466-486. doi:10.1016/ j.jclepro.2019.03.106

Uctug, G., Modi, D. N., Modi, D. N., and Mavituna, F. (2017). Life Cycle Assessment of Biodiesel Production from Microalgae: A Mass and Energy Balance Approach in Order to Compare Conventional with In Situ Transesterification. Ijcea 8, 355-356. doi:10.18178/ijcea.2017.8.6.683

Conflict of Interest: The authors declare that the research was conducted in the absence of any commercial or financial relationships that could be construed as a potential conflict of interest.

Publisher's Note: All claims expressed in this article are solely those of the authors and do not necessarily represent those of their affiliated organizations, or those of the publisher, the editors and the reviewers. Any product that may be evaluated in this article, or claim that may be made by its manufacturer, is not guaranteed or endorsed by the publisher.

Copyright (c) 2021 Arguelles-Arguelles, Amezcua-Allieri and Ramírez-Verduzco. This is an open-access article distributed under the terms of the Creative Commons Attribution License (CC BY). The use, distribution or reproduction in other forums is permitted, provided the original author(s) and the copyright owner(s) are credited and that the original publication in this journal is cited, in accordance with accepted academic practice. No use, distribution or reproduction is permitted which does not comply with these terms. 